\title{
Transfer of Self-Leadership Skills Within the Dutch Police: a Three-Wave Study
}

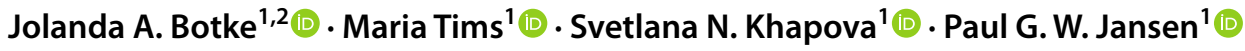

Accepted: 10 September 2021 / Published online: 21 September 2021

(c) The Author(s) 2021

\begin{abstract}
This three-wave study examined the training-to-work transfer process of a self-leadership skills training programme for crime scene investigators working for the Dutch police force. The transfer process is complex and depends on numerous factors. Two important steps forward are taken in the present study. First, we take into account all transfer steps in one study to gain insights into the transfer process, and second, by being specific about the work situation in which transfer outcomes should occur, we address the "criterion problem" that is often mentioned in transfer research. Based on the Ability Motivation Opportunity model, we hypothesised that the posttraining transfer process starts with being motivated to transfer and that this motivation increases the use of self-leadership during work. Another aspect that may facilitate the use of trained skills is supervisor support, as it offers opportunities to use self-leadership skills during work. In turn, self-leadership skills at work were hypothesised to lead to increased work performance. We tested our transfer model in two different work situations experienced by crime fighters. Our findings show that the use of self-leadership skills is positively related to the detached concern of crime fighters in specific situations. Additionally, our findings show that the use of self-leadership skills mediates the relation between the motivation to transfer and work performance in specific situations. Finally, our findings show that including different transfer steps (i.e. the motivation to transfer, use of skills, and performance), different performance measures, and different work situations in the transfer process provides more insight into when and how transfer-to-work after training occurs. These findings suggest that if organisations aspire to improve such transfer, then they should be specific about the intended posttraining behaviours and performance and the situations in which these outcomes should emerge.
\end{abstract}

Keywords Transfer of soft skills training · Self-leadership training · Context-specific transfer · Motivation to transfer · Supervisor support behaviours

Training is considered essential for the quality of work performance in dangerous or challenging jobs, such as those of health professionals and first responders (e.g. fire brigade, police, and ambulance professionals) (Adang 2012; Salar et al. 2017). However, for training to be effective, the skills from the training need to actually be used during the work itself. Only in this way can the use of the skills lead to performance results (Saks et al. 2014). Several studies have confirmed the relation between trained skills and improved performance (e.g. Brown

Jolanda A. Botke

j.a.botke@vu.nl

1 School of Business and Economics, Vrije Universiteit Amsterdam, De Boelelaan 1105, 1081 HV Amsterdam, The Netherlands

2 Department of Human Resource Studies, Tilburg University, Tilburg, The Netherlands and Warren 2009; Sparr et al. 2017; Tuleja and Roberts 2011). However, other studies found no relation between the use of skills after training and (improved) performance results (e.g. Tuleja and Roberts 2011). Some authors argue that the training might not affect performance via the deployment of skills; rather, it is the worker's higher motivation (as a result of the training) that increases his or her performance (e.g. De Grip and Sauermann 2013; Gegenfurtner 2013). A major gap in the research on the transfer of training is a profound overview of stages in the posttraining transfer process (Botke et al. 2018) and a focus on the actual context in which transfer occurs and how it occurs (cf. Baldwin et al. 2017). Consequently, scholars and practitioners still have a limited understanding of trainingto-work transfer, and organisations fail to optimise this transfer.

In this study, we address this gap in the literature by examining the full training-to-work transfer process. Based on the Ability Motivation Opportunity (AMO) model (Appelbaum 
et al. 2000), we theorize that the posttraining transfer process consists of three separate transfer stages. After a training in which participants gain the "Ability", trainees should be motivated to transfer the knowledge and skills from the training ("Motivation", the first stage of transfer). Additionally, we expect that supervisor support plays a key role during the first stage of transfer by providing "Opportunities to use" trained skills during work (Govaerts et al. 2017a, b). This motivation and opportunity to use learned skills should lead to the actual use of skills during work (second stage). Practising the skills should finally lead to increased performance (third stage) (cf. Botke et al. 2018).

Our study focuses on the training-to-work transfer of selfleadership training for crime scene investigators. Selfleadership has been defined as "a comprehensive self-influence perspective that concerns leading oneself towards performance of naturally motivating tasks as well as managing oneself to do work that must be done but is not naturally motivating" (Manz 1986, p. 589). Self-leadership is generally conceptualised as a skill or capability to engage in specific sets of prescriptive self-influence strategies (Neck and Houghton 2006). We specifically focus on emotional self-leadership, which refers to the self-influence of emotions (Manz et al. 2016). Previous research has addressed the importance of emotional self-leadership skills for police professionals (e.g. Le Scanff and Taugis 2002; Williams et al. 2010) since such skills help to increase resilience to work stress by attenuating acute stress responses (Arnetz et al. 2009; Berking et al. 2010). Emotional self-leadership skills have demonstrated incremental utility above and beyond standard police training methods (Arnetz 2012; Arnetz et al. 2009). Consequently, we suggest that emotional self-leadership skills may help crime scene investigators perform in challenging situations because emotional selfleadership skills help to regulate emotions that come with such situations (Manz et al. 2016).

Notably, in the transfer process, increased performance depends on the specific work situation in which the new skills are applied (Barnett and Ceci 2002). For example, the use of skills in an individual situation may be more (or less) difficult than using the same skill in a team context. Previous transfer research refers to this as the "criterion problem", which suggests that research should be clear about what is expected to change as a function of the training and about the settings or situations in which trainees should show adaptability in transferring and effectively using the newly acquired skills (Ford 1997; Gegenfurtner 2011). To address this suggestion, we study the three-stage transfer process in teamwork situations, namely, "cooperation with other disciplines", and an individual work situation of crime fighters, namely, "making a police report". We expect transfer outcomes to occur in both situations. Moreover, testing transfer outcomes in two different situations helps to establish the way in which the specific work situation affects the transfer outcomes.

This paper makes several important contributions to the literature. By studying the full transfer process (i.e. the motivation to transfer, use of skills, and performance) in specific work situations and by focusing on how transfer occurs in a specific situation for a specific target group, we address the previously mentioned "criterion problem". Additionally, we focus on the calls from Patterson et al. (2012) and Janssens et al. (2021) to evaluate the efficacy of stress management interventions among police officers in a multi-wave study. Furthermore, we address Baldwin, Ford, and Blume's call for a "more consumer-centric mindset in transfer research" (Baldwin et al. 2017, pp. 25-26). First, we do this by focusing on the applicability of the findings from transfer research and by providing suggestions on how to design and execute effective training interventions. Second, we include the actual context of where and how learning and transfer occur. Finally, by focusing on supervisor support behaviours that may facilitate the initial transfer, we address an important antecedent of posttraining transfer (Eisenberger et al. 1986; Govaerts et al. 2017a, b; Nijman et al. 2006; Rhoades and Eisenberger 2002) since the supervisor may be in the position to lower the barriers of transfer, such as by providing the proper context to practice new skills, which influences workload and autonomy (Rhoades and Eisenberger 2002) and assures a learning-supportive work climate (Nikolova et al. 2014).

\section{Motivation to Transfer: the Start of Posttraining Transfer}

The AMO model (Appelbaum et al. 2000) suggests that how a training intervention will affect performance depends not only on the knowledge and skills of the professional (in our case, the skills learned during the training) but also on the will or attitude to engage in the behaviours (the motivation to transfer these skills). The motivation to transfer is defined as the trainee's desire to apply the skills and knowledge gained during training to the workplace (Burke and Hutchins 2007; Cheng and Hampson 2008) and includes the transfer of knowledge and skills and attitudes, beliefs, and utility values (Gegenfurtner 2013). If the motivation to transfer (transfer stage 1) is low, then the use of skills (transfer stage 2) will stay behind, and consequently, performance after training (transfer stage 3) will not improve (Gegenfurtner et al. 2009). Earlier research on the transfer of training addressed the relation between the motivation to transfer and the posttraining use of skills. Among others, Van der Locht et al. (2013) and Massenberg et al. (2015) provided evidence for the relation between the motivation to transfer and the posttraining use of skills. In a cross-sectional study, Van der Locht et al. (2013) 
studied the transfer results of 595 Dutch managers who participated in a management training program. They found the motivation to transfer to be a key variable in the level of the transfer of training. Massenberg et al. (2015) studied the transfer results of blue-collar workers in two mediumsized companies in Germany. They found that the motivation to transfer was significantly related to behavioural change 6 weeks after 1-day team reflexivity training. Therefore, the motivation to transfer represents the first stage of transfer (Botke et al. 2018), and we test the following hypothesis:

Hypothesis 1 The motivation to transfer increases the use of emotional self-leadership skills after training.

\section{Supervisor Behaviour During Posttraining Transfer}

Additionally, based on the AMO model, we expect that the opportunity to use skills is important during posttraining transfer (Botke et al. 2018). The supervisor of the trainee plays a key role in providing opportunities to perform (Govaerts and Dochy 2014). Supervisors may facilitate practice opportunities, for example, by including participants in planning and decision making, chairing meetings, broadening their roles, and encouraging them to develop and try new ideas (Lancaster et al. 2013). As such, a positive relationship between supervisor support and the use of trained skills can be expected. In their meta-analysis on the transfer of training, Huang et al. (2015) confirmed the positive relationship between supervisor support and the extent to which trainees utilise newly acquired competences on the job. Additionally, other authors noted a strong positive correlation between supervisor support and training transfer (e.g. Grossman and Burke-Smalley 2018; Van den Bossche et al. 2010). However, some studies have found nonsignificant (e.g. Hutchins et al. 2013a, b; Massenberg et al. 2017) or even negative relationships (e.g. Facteau et al. 1995; Nijman et al. 2006) between supervisor support and transfer outcomes. According to Govaerts and Dochy (2014, p. 79), "discrepancies in the results are conceivably due to different ways in which the construct of supervisor support has been conceptualised and subsequently operationalised in the different studies".

Accordingly, for this study, we examine specific supervisor support behaviours during transfer. Based on Nijman (2004), we focused on two specific posttraining supervisor support behaviours, namely, appraisal supervisor support and emotional supervisor support during the initial transfer (transfer stage 1). Initial transfer refers to the initial attempts of trainees shortly after the training to start using skills from the training in the work environment (Foxon 1993; Laker 1990). Appraisal supervisor support involves the provision of information that is relevant to an individual's self-evaluation (House 1981;
Nijman 2004). Individuals use information from others, for example, supervisors, to evaluate their own opinions and abilities. Appraisal supervisor support refers to information that provides a positive evaluation, for example, giving compliments or providing feedback about the use of new skills during work. Its main - theoretical - benefits are that appraisal supervisor support decreases perceived deviancy, allows the acceptance of feelings, provides favourable comparisons, and increases feelings of being able to handle problems (Cohen et al. 2000). Consequently, employees can fully benefit from the intervention because they feel rewarded when they start using the skills from the training during work. To illustrate, Lee et al. (2014) found that supervisor reward behaviours in a Korean insurance company had significant effects on the degree to which trainees used the knowledge, skills, and attitudes that they had gained through training at work three months after a training.

Emotional supervisor support consists of the availability of persons who can listen sympathetically when one is facing difficulties or problems and who can provide empathy, care, love, and trust (Nijman 2004). For example, a supervisor can emotionally support a trainee during transfer by creating a work climate that is open to change, showing confidence in successful training participation and the transfer of training, and indicating an understanding of possible difficulties in using new knowledge and skills on the job (Nijman and Gelissen 2011). Consequently, employees can fully benefit from the intervention because they feel protected and supported when they start using the skills from the training during work. The results of a transfer study by $\mathrm{Ng}$ (2015) on the role of supervisors in Malaysia suggest that emotional support from supervisors during posttraining transfer increased the application of new learning on the job because reassuring employees that they can improve work performance through learning enhances employee self-confidence. Accordingly, we test the following hypothesis:

Hypothesis 2 Appraisal supervisor support (a) and emotional supervisor support (b) increase the use of emotional self-leadership skills after training.

\section{The Relation Between Using Emotional Self-Leadership Skills and Detached Concern}

Self-leadership theory explains the process through which employees motivate themselves and employ self-direction (Lovelace et al. 2007). Based on social cognitive theory (Bandura 1986), self-leadership can help employees "better manage their thoughts, behaviours, and environment to create a better workplace for improved results" (Goldsby et al. 2020, p. 38). Emotional self-leadership is specifically focused on the self-influence of emotions (Manz 2015). Referring to 
Fredrickson's broaden-and-build theory (Fredrickson 2004), emotional self-leadership is focused on reducing negative emotions and creating positive emotions because such positive emotions can expand potential options for thought and action, while negative emotions tend to reduce such options. In line with this theory, Manz et al. (2016) suggest that the use of emotional self-leadership skills during work may increase the performance of professionals in challenging situations because these skills help them manage their emotions in such situations. The current study focuses on the effects of emotional self-leadership training on detached concern and dealing with a heavy workload. Keeping detached concern and dealing with a heavy workload are found to be important for the work of police professionals (see, for example, Chiorri et al. 2015; Oron-Gilad et al. 2008; Van Gelderen et al. 2014).

Detached concern refers to a professional balance that blends concern with distance (Lampert and Glaser 2018). In this process of balancing empathy and detachment, emotion regulation is important (Dormann and Zapf 2004), as the main purpose of detachment is an intrapersonal regulation process of emotions in which professionals retain a personal boundary between them and their clients (Lampert et al. 2019). In this study, we focused on the effect of using six different emotional self-leadership skills, specifically, the behavioural-focused strategies of "self-goal setting" and "self-observation", the cognitive-focused strategies of the "evaluation of values and beliefs", "self-imagery" and "self-talk", and the physiologicalfocused strategy "deep relaxed breathing" (see Table 1), since these skills are found to be related to the emotional regulation that is needed for a balanced detached concern. More specifically, the skill "self-goal setting" is important for goal pursuit, which is an important resource for keeping detached concern (Dormann and Zapf 2004). The skill "self-observation" helps to obtain information about current behaviour and performance levels and supports employees in self-setting effective (future) goals (Shahin and Salehzadeh 2013). The skill the "evaluation of values and beliefs" helps employees understand the success, failure, or consequences of their behaviour. This information helps to sustain or modify goals or efforts to achieve these goals (Parker et al. 2010). The skill "self-imagery" allows us to better monitor, compare, and regulate current and desired states. This increases the feeling of self-control, which is an important resource for keeping detached concern (Decety et al. 2014). The skill "self-talk" is important for staying optimistic and increases the feeling of self-control by using positive self-talk (Decety et al. 2014; Dolbier et al. 2001). Finally, the skill "deep relaxed breathing" creates an awareness of breathing. This awareness of breathing helps to determine what is going on in one's mind concerning thoughts, concepts, and emotions, without labelling them as "good" or "bad" (Karssiens et al. 2014) and as such, helps to regulate emotions, which is key for keeping detached concern. Thus, using the six emotional self-leadership skills (transfer stage 2) may help to regulate the emotional reaction to a situation (Nesbit 2012) and accordingly, support the process of finding the right dose between empathic concern for the client and detachment for oneself, which results in a balanced detached concern (transfer stage 3). Thus, we test the following hypothesis:

Hypothesis 3 The use of the six emotional self-leadership skills is positively related to keeping detached concern.

\section{The Relation Between Using Emotional Self-Leadership Skills and Dealing with a Heavy Workload}

Fredrickson's broaden-and-build theory (2004) suggests that individuals who experience positive affect are more likely to adopt creative responses to potential challenges in the environment. Previous research alludes to a positive

Table 1 Overview of the six emotional self-leadership skills

\begin{tabular}{ll}
\hline Emotional self-leadership skill & $\begin{array}{c}\text { Description of the skill } \\
\text { Self-goal setting }\end{array}$ \\
$\begin{array}{l}\text { Establishing goals that are aimed at the fulfilment of personal goals or organisational goals (Marques-Quinteiro } \\
\text { and Curral 2012) } \\
\text { Behaviour observation and reflection with regard to the effectiveness of own performance in relation to the } \\
\text { task, the team and the organisation (Marques-Quinteiro and Curral 2012) }\end{array}$ \\
Evaluation of values and beliefs "Through a process of self-analysis, individuals may identify, confront, and replace dysfunctional beliefs and \\
assumptions with more rational ones" (Houghton and Neck 2002, p. 674) \\
Cognitive simulate how tasks will be performed and create a mental image of the desired outcomes (Neck and \\
Houghton 2006) \\
What we covertly "tell ourselves", either mentally or out loud (Neck and Manz 2016). The self-talk works as a \\
distractor (i.e. get one's mind off a negative event or emotion) \\
Concentrating on exhaling as much air as possible at the beginning of the breath. This causes the lungs to \\
automatically take in more air on the in breath, which has a calming affect resulting from the intake of more \\
oxygen (Manz et al. 2016)
\end{tabular}


relation between self-leadership training and better dealing with a heavy workload. For example, Goldsby et al. (2020) suggest that self-leadership skills may help to moderate the perceived time pressure of nurses. Consequently, we imply that using the six emotional selfleadership skills not only holds promise as a direct performance-enhancing intervention but also will help to deal with heavy workload situations by enabling the handling of subjective feelings of work overload. More specifically, the skill "self-goal setting" will help to deal with a heavy workload, as a high workload necessitates behaviours such as persisting and resisting temptations to achieve task-related goals (Schmidt and Diestel 2015). Additionally, professionals who are trained to set goals and reward themselves upon reaching the goals are less likely to have problems dealing with a heavy workload, as they are less likely to feel overwhelmed (Unsworth and Mason 2012). The skill "self-observation" helps concentration on one's awareness. This kind of awareness is an essential measure to change or exclude ineffective behaviours and focus on what truly has to be done (Shahin and Salehzadeh 2013). The skill "evaluation of values and beliefs" helps professionals remain flexible to adapt to changing situational demands, such as unexpected stressors that can increase (the feeling of) a heavy workload (Anton et al. 2018). Additionally, addressing the stressful circumstances (the heavy workload situation) in one's mind (the "self-imagery" skill) helps to successfully respond to (potential) stressors and deal with the situation (Neck et al. 2013). The skill "self-talk" helps not only to overcome the feeling of difficulty but also to estimate the effort. Positive self-talk acts as a resource for effort exertion (Efklides et al. 2006). Finally, the skill "deep relaxed breathing" helps the ability to stay calm in a potentially stressful situation (Manz et al. 2016). Thus, we suggest that by using the six emotional self-leadership skills (transfer stage 2), individuals can better manage the feeling of work overload. This will consequently help them to better deal with a heavy workload (transfer stage 3). Accordingly, we test the following hypothesis:

Hypothesis 4 The use of the six emotional self-leadership skills is positively related to dealing with a heavy workload.

\section{The Mediating Role of Emotional Self-Leadership Skills}

The motivation to transfer and supervisor support have been shown to positively affect performance (e.g. Colquitt et al. 2000; Yamkovenko and Holton 2010). However, both the motivation to transfer and supervisor support are found to be related to initial or short-term transfer (Al-Eisa et al. 2009; Hutchins et al. 2013a, b). Maintenance or longterm transfer requires applying and maintaining newly learned skills on the job (Laker 1990). During the stage of transfer maintenance, a trainee makes a conscious choice to use the skills from the training whenever it is appropriate (Foxon 1993). This eventually leads to the unconscious use of these skills. When skills are integrated into job behaviour, transfer occurs in full (Foxon 1993). Therefore, in line with Laker (1990), we suggest that the effect of the motivation to transfer (transfer stage 1) and supervisor support on performance three months after training (transfer stage 3 ) are fully mediated by the use of self-leadership skills (transfer stage 2). Thus, we expect that the motivation to transfer and supervisor support behaviours impact the use of emotional self-leadership skills. This use of emotional self-leadership skills, in turn, is related to performance (i.e. keeping detached concern and dealing with a heavy workload). Therefore, we test the following hypotheses:

Hypothesis 5 The use of emotional self-leadership skills mediates the relationship between keeping detached concern and (a) the motivation to transfer, (b) appraisal supervisor support, and (c) emotional supervisor support.

Hypothesis 6 The use of emotional self-leadership skills mediates the relationship between dealing with a heavy workload and (a) the motivation to transfer, (b) appraisal supervisor support, and (c) emotional supervisor support.

Figure 1 depicts the overall hypothesised model. We tested our transfer model in a teamwork situation and an individual work situation. We expect transfer outcomes to occur in both situations. Moreover, testing transfer outcomes in two different situations enables us to establish the way in which the specific work situation affects the transfer outcomes.

\section{Method}

\section{Participants and Procedure}

Our sample consisted of approximately 2,000 crime scene investigators working for different departments of the Dutch police who signed up for self-leadership training between July 2016 and June 2017. Participation in the training was mandatory for all police professionals as part of the "Strengthening Professional Resilience" programme of the Dutch police. An overview of possible training dates and locations was presented by the training provider. Professionals could choose when to follow the training by subscribing to one of the dates available for the training. After the 


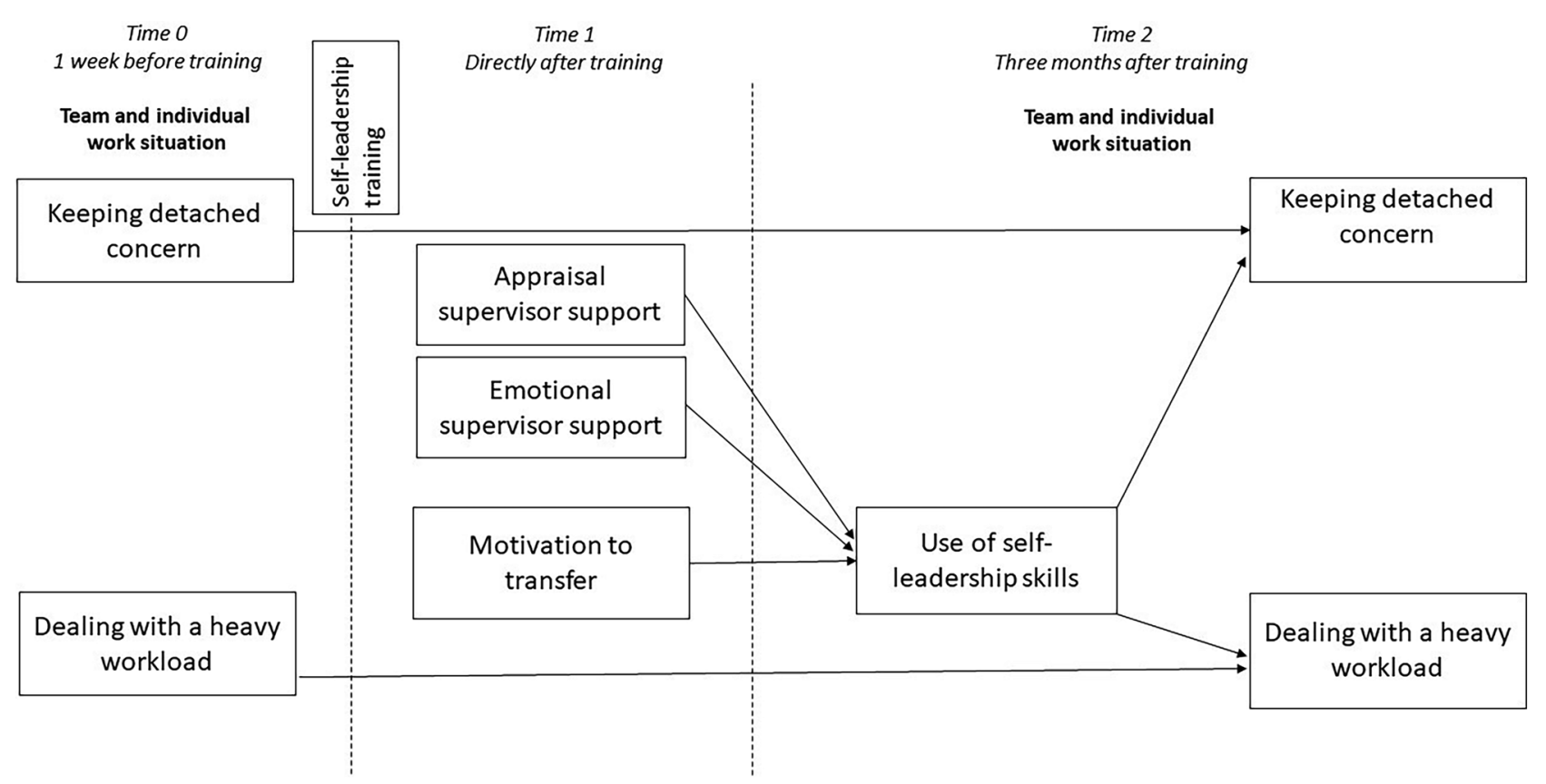

Fig. 1 Conceptual model

management agreed to participate in the study, professionals who signed up for the training during the study period were informed about the research and were asked to participate. The participants' responses were anonymous and voluntary, and we encouraged them to respond by sending out a reminder email one week after the initial invitation.

After closing the questionnaire, 1,152 participants had completed the T0 questionnaire, 789 participants had completed the T1 questionnaire, and 433 had completed the T2 questionnaire. In total, 155 respondents completed the survey at all three points in time. From discussions with the quality manager of the training, we found that three reasons may explain the low response rate. First, links to the online questionnaire were sent out via e-mail. Therefore, answering the questionnaires competed with other more urgent tasks of the training participants. Second, the link to the online questionnaire did not work if training participants were using telework facilities (e.g. working from home). Although instructions were provided on how to copy the link into their own browser, this may have prevented training participants from completing the questionnaire. Third, it is uncommon for training participants to receive more than one questionnaire on the same training. Usually, questionnaires are completed directly after training. This may explain at least partly why the response rates declined at $\mathrm{T} 2$.

Low return rates are less likely to be biased when the respondent characteristics do not differ from those of nonrespondents (Krosnick 1999). As information on the overall population of crime scene investigators could not be obtained, we compared the subgroup of respondents who answered all three questionnaires $(N=155)$ with the subgroup that answered only T1 or T1 and T0 $(N=789)$. An independent t-test showed no significant differences between the group that completed all three questionnaires and the group that completed only the T1 or T1 and T0 questionnaires in terms of gender $(t(942)=1.34, p=.18)$, age $(t(942)=-.91, p=.37)$, and organisational tenure $(t(942)=-.66, p=.51)$. In the final sample of 155 respondents, $62.7 \%$ were male, and the average age was 49.80 years $(S D=9.13$; range $=24-66$ years $)$. These respondents had worked for a relatively long time for the Dutch police $(M=24.28 ; S D=12.18$; range $=0-46$ years $)$. The sex distribution and the average age in our sample were in line with those of the Dutch police force $(66 \%$ male, average age of 45 years) (Politie, n.d.). The average tenure in our sample was higher than the average of the Dutch police force (average tenure of 15 years) (Huijs et al. 2014).

As the social context may influence the transfer process (Barnett and Ceci 2002), we specified an individual work situation and a teamwork situation to test our model. For this purpose, we identified the most critical team and individual situation in the work of crime fighters in two expert sessions with a total of approximately 20 staff members from the Netherlands Police Agency and the National Criminal Intelligence Department. A work situation was defined as critical if performance was crucial for overall job success. The most critical teamwork situation ("work situation 1") that was identified was called "cooperation with other disciplines". During the expert sessions, the participants mentioned that the different focuses, aims, and working 
methods of disciplines often make it difficult and stressful to perform in the best way in this work situation. Additionally, Huisman et al. (2016) mentioned that "the increasing complexity of crime fighting means that more diverse disciplines are included in the process of solving crimes. Working in multidisciplinary teams and networks will be more important than ever; effective cooperation between very different professionals will be a crucial factor for success" (p. 45). The most critical individual work situation ("work situation 2") that was identified was called "making a police report". An accurate police report is the start of a chain of action in which the public prosecutor and judge(s) decide how to follow up. As such, the quality of the report is important. During the expert sessions, the participants mentioned that time constraints, other work priorities, and system constraints sometimes make it difficult and stressful to generate the best report possible.

The work situations were used at $\mathrm{T} 0$ and $\mathrm{T} 2$. The participants were asked if they had been in each work situation in the last three months before they were asked questions about their use of skills and performance in the work situation. If they had not been in the situation, then they did not answer questions on this situation. From the 155 participants, 98 participants provided ratings for their use of skills and performance (keeping detached concern and dealing with a heavy workload) in work situation 1 (the teamwork situation), and 97 participants provided ratings for their use of skills and performance (keeping detached concern and dealing with a heavy workload) in work situation 2 (the individual work situation).

\section{The Self-Leadership Training}

The 2-day self-leadership training included the six strategies as previously described. During the first day of the training, the training participants learned how to set self-goals (the behaviour-focused strategy of "goal-setting") by using the SMART method and how to use such goals in challenging situations. The SMART method includes formulating specific, measurable, acceptable, realistic, and time-bound goals. For example, they learned that speaking your goals out loud helps to focus on what you are aiming for and makes it possible for others to help you reach your goal. Next, the constructive thought pattern strategy of "evaluating beliefs and assumptions" was explained and practised by using the "action reflection" model. The action reflection model provides a framework for reflective practice, where a problem in practice is identified and forms the basis of inquiry (e.g. What did I do? What did I experience?), followed by change and further reflection (e.g. What will I do different the next time I am in such a situation?). Then, the training participants were taught how to prepare for different scenarios by practising the situation, behaviours, and responses to such behaviours in a visualisation task (the constructive thought pattern strategy of "self-imagery"). Finally, they were taught how to create an awareness of breathing with simple tools for monitoring heart rhythm coherence (the physiologicalfocused strategy of "deep relaxed breathing"). On the second day of the training, the training participants learned and practised how to recognise their focus of attention in different situations and different ways to stay focused and not become distracted by irrelevant information (the behavioural-focused strategy of "self-observation"). Additionally, they learned how to recognise negative thoughts and emotions and how to bend these towards more positive appraisals of stressful event experiences (the constructive thought pattern strategy of "self-talk").

The training was led by two professional trainers and conducted during regular work hours. In line with Russ-Eft (2002), the training participants received a pretraining package that included information about the relevance of the training and some noncompulsory pretraining exercises. At the beginning of the training, an overview of the training content was presented as an "advance organiser" to allow the training participants to organise and retain the material to be learned. Based on Kirwan (2009), the training included a variety of training and learning methods to increase the understanding of the participants and to enable the transfer of the acquired knowledge and skills in different ways. Additionally, the training included a significant amount of time to practice and examples of desired and undesired applications (Kirwan 2009).

\section{Measures}

Unless otherwise indicated, a five-point response scale was used for all items that ranged from 1 (strongly disagree) to 5 (strongly agree). All scales were pilot-tested by asking internal programme managers to fill in the draft questionnaire and provide feedback; minor revisions in the expression and ordering of items were reflected in the final version of the instrument.

The motivation to transfer (T1) was measured by using the four-item subscale for the motivation to transfer from the Learning Transfer Inventory System (Holton III et al. 2000). A sample item is "I get excited when I think about trying to use my new learning on the job". The Cronbach's alpha was .93.

The use of self-leadership skills (T2; work situations 1 and 2) was measured by using a self-developed scale of six items, with one on each skill from the training (evaluating beliefs and assumptions, self-goal setting, visualising, energy management, self-observation, and self-talk). A sample item is "The last time I was in this situation, I purposely converted 
obstructing thoughts into positive thoughts". A 10-point response scale that ranged from 1 (not used) to 10 (often used) was used. As the social context (i.e. the specific work situation) may influence the transfer to work process (Barnett and Ceci 2002), the use of skills was measured separately for each of the two work situations. The validity of this newly developed measure was examined by using an exploratory factor analysis (a principal component method with direct oblimin rotation). One factor with an eigenvalue of $>1$ was extracted, which explained $60.4 \%$ of the variance for work situation 1 and $68.5 \%$ of the variance for work situation 2. All factor loadings were .70 or higher. The Cronbach's alphas were .89 (work situation 1) and .91 (work situation 2). These findings provide support for the validity and reliability of this measure.

Performance (T0 and T2; work situations 1 and 2) was measured by assessing two performance requirements, namely, "keeping detached concern" and "dealing with a heavy workload". Keeping detached concern was measured with a four-item scale that was developed as part of the Resilience Monitor for crime scene investigators (Delahaij et al. 2014). For our research, we slightly adapted the items. The original scale asks about the distance between and emotional involvement with "victims". Because our participants were not always directly confronted with victims, we changed the term "the victims" to a more general concept of "the case and the people involved". A sample item is "The last time I was in this situation, I kept enough professional distance to the case and to people involved". Dealing with a heavy workload was measured by using a three-item scale based on the raw NASA Task Load Index (Hart and Staveland 1988). Based on the specific situation of our target group, we selected the items on temporal demand, perceived performance, and effort. A sample item is, "The last time I was in this situation, it took much energy to perform properly". The Cronbach's alpha for keeping detached concern at T0 was .79 (work situation 1) and .91 (work situation 2) and at T2 was .65 (work situation 1) and .78 (work situation 2). For T2 situation 1, the Cronbach's $\alpha$ was below .70 because of the relatively small group of respondents. However, for the total $\mathrm{T} 2$ group $(N=433)$, the Cronbach's $\alpha$ was .81. The Cronbach's alpha for dealing with a heavy workload at $\mathrm{T} 0$ was .75 (work situation 1) and .85 (work situation 2) and at T2 was .73 (work situation 1) and .86 (work situation 2).

Supervisor support behaviour (T1) was measured by assessing "appraisal supervisor support" and "emotional supervisor support". Appraisal supervisor support was measured by using the three-item subscale from Nijman (2004). A sample item is "My supervisor indicated that s/he would appreciate it if I would make use of skills from the training during work". Emotional supervisor support was measured with the three-item subscale from Nijman (2004). A sample item is "My supervisor indicated that I could consult him/ her if I would have difficulties using skills from the training during work". The Cronbach's alpha for appraisal supervisor support was .89, and the Cronbach's alpha for emotional supervisor support was .88 .

\section{Analysis}

Analyses of the descriptive statistics, reliabilities, and correlations among the variables were conducted by using SPSS 25.0. Confirmatory factor analyses (CFAs) in AMOS 25.0 were conducted per scale to assess the factor structure of each measure. Then, the proposed measurement model was tested in AMOS to confirm that the factors were distinct. Two alternative models were tested: a model with appraisal supervisor support and emotional supervisor support loaded on one factor (M1) and a model with keeping detached concern and dealing with a heavy workload loaded on one factor and the use of self-leadership skills loaded on a separate factor (M2). To test our hypotheses, we used structural equation modelling (SEM) with a maximum likelihood estimation. The overall $\chi^{2}$ measure, comparative fit index (CFI), incremental fit index (IFI), Tucker-Lewis index (TLI), standardised root mean square residual (SRMR), and root mean square error of approximation (RMSEA) were used to assess the model fit. It is generally suggested that the TLI, IFI, and CFI values should exceed .90 or even .95 for the model to be considered a good fit (Hu and Bentler 1999). Similarly, a value of .06 or less for RMSEA (Browne and Cudeck 1992) and a value of .05 or less for SRMR (Hooper et al. 2008) reflect a good fit.

Because we used self-report measures, we took several precautions to ascertain whether common method variance (CMV) may have been an issue in our study following the suggestions of Tehseen et al. (2017). First, we measured our dependent variables at a separate measurement time, namely, three months later. Second, the anonymity of the respondents was assured, and evaluation apprehension was minimised by using nontrackable personal codes. This can minimise method bias at the reporting stage. Third, we pretested each questionnaire to avoid item ambiguity, which is seen as the most common problem in the comprehension stage of response. After retrieving the data, Harman's single-factor test was conducted in SPSS. In an exploratory factor analysis when all the items were loaded on a single factor, the variance accounted for $22.6 \%$ for situation 1 and $23.0 \%$ for situation 2, which, in turn, was less than the recommended value of 50\% (Podsakoff et al. 2012).

\section{Results}

The descriptive statistics, including the means, standard deviations, and correlations among the study variables, can 
be found in Table 2. The use of self-leadership skills and performance ("keeping detached concern" and "dealing with a heavy workload") were measured in the two situations ( $\mathrm{S} 1$ and $\mathrm{S} 2$ in Table 2). The means, standard deviations, and correlations are reported per situation. As seen in this table, the T1 motivation to transfer was positively correlated with the T2 use of self-leadership skills in work situation 1 $(r=.42, p<.01)$ and work situation $2(r=.28, p<.01)$, and the $\mathrm{T} 1$ appraisal supervisor support was positively correlated with the T2 use of self-leadership skills in work situation $2(r=.22, p<.05)$. The $\mathrm{T} 2$ detached concern in situation 2 was positively correlated with the $\mathrm{T} 2$ use of self-leadership skills in work situation $2(r=.24, p<.05)$. The $\mathrm{T} 2$ detached concern in work situation 1 was positively correlated with the T0 detached concern in work situation $1(r=.35, p<.01)$, and the T2 dealing with a heavy workload in work situation 2 was positively correlated with the T0 dealing with a heavy workload in work situation $2(r=.39, p<.01)$.

Table 2 Means, standard deviations and correlations among the study variables

\begin{tabular}{|c|c|c|c|c|c|c|c|c|c|c|c|}
\hline & & $M$ & $S D$ & 1 & 3 & 3 & 4 & 5 & 6 & 7 & 8 \\
\hline 1 & T1 Motivation to transfer & 3.28 & .76 & & & & & & & & \\
\hline 2 & T1 Emotional supervisor support & 2.66 & .93 & .15 & & & & & & & \\
\hline 3 & T1 Appraisal supervisor support & 2.37 & .96 & $.22^{* *}$ & $.84^{* *}$ & & & & & & \\
\hline 4 & T2 Use of self-leadership skills S1 & 5.56 & 1.54 & $.42^{* *}$ & .18 & .19 & & & & & \\
\hline 5 & T2 Use of self-leadership skills S2 & 5.21 & 1.79 & $.28^{* *}$ & $.25^{*}$ & $.22^{*}$ & $.77^{* *}$ & & & & \\
\hline 6 & T2 Keeping detached concern S1 & 4.02 & .36 & .07 & -.02 & .00 & .20 & .23 & & & \\
\hline 7 & T2 Dealing with a heavy workload S1 & 3.89 & .73 & -.14 & $-.25^{*}$ & $-.27^{* *}$ & -.09 & .04 & $.38^{* *}$ & & \\
\hline 8 & T2 Keeping detached concern S2 & 4.02 & .47 & -.10 & .04 & -.02 & .16 & $.24^{*}$ & $.73^{* *}$ & $.57^{* *}$ & \\
\hline 9 & T2 Dealing with a heavy workload S2 & 3.84 & .77 & -.18 & .06 & .07 & .05 & -.08 & -.09 & -.01 & $.27^{* *}$ \\
\hline 10 & T0 Keeping detached concern S1 & 4.10 & .41 & $-.23^{* *}$ & -.08 & -.13 & .05 & .15 & $.35^{* *}$ & .20 & $.32^{* *}$ \\
\hline 11 & T0 Dealing with a heavy workload S1 & 3.89 & .70 & $-.20 *$ & -.01 & -.07 & -.13 & -.08 & .11 & .15 & .11 \\
\hline 12 & T0 Keeping detached concern S2 & 4.17 & .47 & $-.20 *$ & .03 & .05 & .06 & .07 & .18 & .05 & $.25^{*}$ \\
\hline 13 & T0 Dealing with a heavy workload S2 & 3.78 & .83 & -.16 & $-.20 *$ & -.13 & -.08 & .04 & .05 & .20 & $.28^{* *}$ \\
\hline 14 & Gender $^{\mathrm{a}}$ & 1.32 & .47 & .07 & -.13 & -.14 & $.29 * *$ & .15 & .01 & -.09 & .09 \\
\hline 15 & $\mathrm{Age}^{\mathrm{b}}$ & 49.80 & 9.13 & .08 & .11 & .07 & -.07 & -.00 & .01 & -.00 & .01 \\
\hline \multirow[t]{2}{*}{16} & Tenure $^{\mathrm{b}}$ & 24.28 & 12.8 & -.12 & .07 & .03 & -.09 & -.08 & .11 & .01 & .02 \\
\hline & & $M$ & $S D$ & 9 & 10 & 11 & 12 & 13 & 14 & & 15 \\
\hline 1 & T1 Motivation to transfer & 3.28 & .76 & & & & & & & & \\
\hline 2 & T1 Emotional supervisor support & 2.66 & .93 & & & & & & & & \\
\hline 3 & T1 Appraisal supervisor support & 2.37 & .96 & & & & & & & & \\
\hline 4 & T2 Use of self-leadership skills S1 & 5.56 & 1.54 & & & & & & & & \\
\hline 5 & T2 Use of self-leadership skills S2 & 5.21 & 1.79 & & & & & & & & \\
\hline 6 & T2 Keeping detached concern S1 & 4.02 & .36 & & & & & & & & \\
\hline 7 & T2 Dealing with a heavy workload S1 & 3.89 & .73 & & & & & & & & \\
\hline 8 & T2 Keeping detached concern S2 & 4.02 & .47 & & & & & & & & \\
\hline 9 & T2 Dealing with a heavy workload S2 & 3.84 & .77 & & & & & & & & \\
\hline 10 & T0 Keeping detached concern S1 & 4.10 & .41 & .09 & & & & & & & \\
\hline 11 & T0 Dealing with a heavy workload S1 & 3.89 & .70 & .20 & $.27 * *$ & & & & & & \\
\hline 12 & T0 Keeping detached concern S2 & 4.17 & .47 & .13 & $.61 * *$ & .06 & & & & & \\
\hline 13 & T0 Dealing with a heavy workload S2 & 3.78 & .83 & $.39 * *$ & $.35 * *$ & $.31 * *$ & $.41^{*}$ & & & & \\
\hline 14 & Gender $^{\mathrm{a}}$ & 1.32 & .47 & -.11 & -.07 & .00 & -.08 & -.16 & & & \\
\hline 15 & $\mathrm{Age}^{\mathrm{b}}$ & 49.80 & 9.13 & .01 & -.02 & .09 & .06 & -.02 & & $34 * *$ & \\
\hline 16 & Tenure $^{\mathrm{b}}$ & 24.28 & 12.8 & .04 & .12 & .15 & $.20^{*}$ & .12 & & $46 * *$ & $.74 * *$ \\
\hline
\end{tabular}

$N=155$

$S 1$ work situation $1, S 2$ work situation 2

${ }^{*} p<.05 ; * * p<.01$

${ }^{\mathrm{a}}$ Gender $(1=$ male, 2 =female $)$

${ }^{\mathrm{b}}$ The control variables tenure and age were measured in years 


\section{Confirmative Factor Analysis and Measurement Model}

Confirmatory factor analyses (CFAs) in AMOS were conducted per scale to assess the factor structure of each measure (see Table 3). Appraisal supervisor support, emotional supervisor support, and dealing with a heavy workload were modelled by using three indicators, which means that fit indices are not provided for these scales in separate CFAs because the fit would be perfect, irrespective of the pattern of the factor loadings (Malhotra and Sharma 2008). Based on the outcomes of the separate CFAs, we then examined the total measurement model, which included all the study variables (eight variables). We tested the model in each of the two work situations separately. For both work situations, the fit was suboptimal (for work situation 1: $\chi^{2}=665.24$, $d f=377, \mathrm{TLI}=.84, \mathrm{CFI}=.87, \mathrm{IFI}=.88, \mathrm{RMSEA}=.02$; for work situation $2: \chi^{2}=634.89, d f=377, \mathrm{TLI}=.88, \mathrm{CFI}=.90$, $\mathrm{IFI}=.91$, RMSEA $=.02$ ). All factor loadings were significant, except for the factor loading "The last time I was in this situation, I successfully completed what I had to do", which did not load substantially on dealing with a heavy workload ( $\beta=.09, p=.06)$ and was therefore removed from further analysis. The factor loading "My supervisor did not check my training participation" loaded negatively on appraisal supervisor support and was therefore removed from further analysis. This resulted in a significantly better model fit (for work situation 1: $\Delta \chi^{2}=160.70, \Delta d f=81, p<.01$; for work situation 2: $\left.\Delta \chi^{2}=182.56, \Delta d f=81, p<.01\right)$; this is the "optimised measurement model" in Table 3.

Next, we compared this model with the two alternative measurement models. First, we tested a seven-factor model in which appraisal supervisor support and emotional supervisor support loaded on one factor (M1). This model showed a slightly worse fit than the optimised measurement model (for work situation 1: $\Delta \chi^{2}=16.70, \Delta d f=7, p<.05$; for work situation 2 : $\left.\Delta \chi^{2}=16.52, \Delta d f=7, p<.05\right)$. Consequently, we kept appraisal supervisor support and emotional supervisor support as two distinct variables. Second, we tested a six-factor model in which keeping detached concern (pre- and posttraining) and dealing with a heavy workload (pre- and posttraining) loaded on one factor, and the use of self-leadership skills loaded on a separate factor (M3). Again, this model showed a significantly worse fit than the optimised measurement model (for work situation 1: $\Delta \chi^{2}=42.29, \Delta d f=7, p<.001$; for work situation 2: $\Delta \chi^{2}=85.23, \Delta d f=7, p<.001$ ), which indicates that the performance measures of keeping detached concern and dealing with a heavy workload can be distinguished from one another.

Finally, we tested the hypothesised model, with the T2 use of self-leadership skills mediating the relation between the T1 motivation to transfer and T2 performance (keeping detached concern and dealing with a heavy workload) and between $\mathrm{T} 1$ supervisor behaviour (emotional support and appraisal support) and $\mathrm{T} 2$ performance (keeping detached concern and dealing with a heavy workload). T0 performance (keeping detached concern and dealing with a heavy workload) was included in the model as a covariate. The fit of this model was acceptable (for work situation $1: \chi^{2}=467.49, d f=301, \mathrm{TLI}=.89, \mathrm{CFI}=.91, \mathrm{IFI}=.91$, RMSEA $=.02$; for work situation $2: \chi^{2}=486.74, d f=301$, $\mathrm{TLI}=.91, \mathrm{CFI}=.93, \mathrm{IFI}=.93, \mathrm{RMSEA}=.02$ ).

Table 3 Results of testing the measurement models

\begin{tabular}{|c|c|c|c|c|c|c|c|c|}
\hline & $\chi^{2}$ & $d f$ & $\mathrm{CFI}$ & TLI & IFI & SRMR & RMSEA & $\Delta \chi^{2} / \Delta d f$ \\
\hline Measurement model motivation to transfer $\mathrm{T} 1$ & 16.27 & 2 & .99 & .98 & .99 & .01 & & \\
\hline $\begin{array}{l}\text { Measurement model use of self-leadership skills } \\
\text { T2-S1/S2 }\end{array}$ & $37.05 / 52.40$ & 9 & $.97 / .96$ & $.94 / .93$ & $.97 / .96$ & $.04 / .04$ & & \\
\hline $\begin{array}{l}\text { Measurement model keeping detached concern } \\
\text { T0_-S1/S2 }\end{array}$ & $\begin{array}{l}6.19 / 1.08 \\
1.62 / 8.42\end{array}$ & $\begin{array}{l}2 \\
2\end{array}$ & $\begin{array}{l}.99 / 1.00 \\
1.00 / .98\end{array}$ & $\begin{array}{l}.99 / 1.00 \\
1.00 / .95\end{array}$ & $\begin{array}{l}1.00 / 1.00 \\
1.00 / .98\end{array}$ & $\begin{array}{l}.01 / .00 \\
.01 / .03\end{array}$ & & \\
\hline \multicolumn{9}{|l|}{$\begin{array}{l}\text { Measurement model keeping detached concern } \\
\mathrm{T} 2-\mathrm{S} 1 / \mathrm{S} 2\end{array}$} \\
\hline Total measurement model $-\mathrm{S} 1 / \mathrm{S} 2$ & $629.95 / 634.89$ & 377 & $.88 / .90$ & $.85 / .88$ & $.89 / .91$ & & $.02 / .02$ & \\
\hline $\begin{array}{l}\text { Optimised measurement model ( } 2 \text { items } \\
\text { excluded) - S } 1 / \mathrm{S} 2\end{array}$ & $469.25 / 452.33$ & 296 & $.92 / .94$ & $.89 / .92$ & $.92 / .94$ & & $.02 / .02$ & $\begin{array}{l}\text { S1: } 160.70 / 81 * * * \\
\text { S2: } 182.56 / 81^{* * *}\end{array}$ \\
\hline Alternative measurement model $\mathrm{M} 1-\mathrm{S} 1 / \mathrm{S} 2$ & $485.95 / 468.85$ & 303 & $.91 / .93$ & $.89 / .92$ & $.91 / .93$ & & $.02 / .02$ & $\begin{array}{l}\text { S1: } 16.70 / 7^{*} \\
\text { S2: } 16.52 / 7^{*}\end{array}$ \\
\hline Alternative measurement model M2-S1/S2 & $511.54 / 537.56$ & 303 & $.90 / .90$ & $.87 / .88$ & $.90 / .91$ & & $.02 / .02$ & $\begin{array}{l}\text { S1: } 42.29 / 7 * * * \\
\text { S2: } 85.23 / 7 * * *\end{array}$ \\
\hline Hypothesised model-S1/S2 & $467.49 / 486.74$ & 301 & $.91 / .93$ & $.89 / .91$ & $.91 / .93$ & & $.02 / .02$ & \\
\hline
\end{tabular}

$S 1$ work situation $1, S 2$ work situation 2 


\section{Hypothesis Tests}

In Hypothesis 1, we expected the T1 motivation to transfer to increase the $\mathrm{T} 2$ use of self-leadership skills after training. As Table 4 shows, the T1 motivation to transfer was positively related to the $\mathrm{T} 2$ use of emotional self-leadership skills for both work situation $1(\beta=.49, p<.001)$ and work situation $2(\beta=.22 ; p<.05)$. Thus, Hypothesis 1 can be confirmed.

In Hypothesis 2, we expected (a) T1 appraisal supervisor support and (b) T1 emotional supervisor support to increase the T2 use of emotional self-leadership skills after training. $\mathrm{T} 1$ appraisal supervisor support was not related to the T2 use of self-leadership skills for work situation $1(\beta=.13$, $p=.78)$ or for work situation $2(\beta=.16 ; p=.72)$. Additionally, Table 4 shows that $\mathrm{T} 1$ emotional supervisor support was not related to the $\mathrm{T} 2$ use of self-leadership skills for work situation $1(\beta=-.09, p=.85)$ or for work situation 2 $(\beta=.05 ; p=.91)$. Thus, Hypotheses $2 \mathrm{a}$ and $2 \mathrm{~b}$ were not confirmed. Consequently, Hypotheses 5b, 5c, 6b, and 6c cannot be confirmed since no mediation is possible.

In Hypothesis 3, we expected that the T2 use of emotional self-leadership skills would be positively related to $\mathrm{T} 2$ keeping detached concern. As Table 4 shows, the T2 use of emotional self-leadership skills was not related to T2 keeping detached concern for work situation $1(\beta=.11$, $p=.42$ ). In contrast, the $\mathrm{T} 2$ use of emotional self-leadership skills in work situation 2 was positively related to T2 keeping detached concern $(\beta=.31, p<.05)$. Thus, Hypothesis 3 can be partly confirmed (only for work situation 2 , i.e. the individual work situation).

In Hypothesis 4, we expected that the $\mathrm{T} 2$ use of emotional self-leadership skills would be positively related to $\mathrm{T} 2$ dealing with a heavy workload. Our findings show that the T2 use of emotional self-leadership skills was not related to T2 dealing with a heavy workload for work situation $1(\beta=.08$, $p=.59)$ or for work situation $2(\beta=-.12, p=.28)$. Thus, Hypothesis 4 is not confirmed. Consequently, Hypothesis $6 \mathrm{a}$ cannot be confirmed since no mediation is possible.

In Hypothesis 5a, we expected that the T2 use of emotional self-leadership skills would mediate the impact of the T1 motivation to transfer on T2 keeping detached concern. Given the results of Hypothesis 3 that there was no relationship between the $\mathrm{T} 2$ use of emotional self-leadership skills and $\mathrm{T} 2$ keeping detached concern in work situation 1, we proceeded to test this for work situation 2. For work situation 2 , the use of skills was related to keeping detached concern (Hypothesis 3). Additionally, the direct relation between the $\mathrm{T} 1$ motivation to transfer and $\mathrm{T} 2$ keeping detached concern was nonsignificant $(\beta=-.07, p=.57)$. This indicates that for work situation 2 , the T2 use of emotional self-leadership skills fully mediated the relation between the T1 motivation to transfer and T2 keeping detached concern. Thus, Hypothesis 5a can be partly confirmed (only for work situation 2, the individual work situation). However, notably, T0 keeping detached concern was positively related to $\mathrm{T} 2 \mathrm{keep}-$ ing detached concern in work situation $2(\beta=.33, p<.01)$, which suggests that the performance after training in work situation 2 can be at least partly explained by the performance before training.

An additional analysis showed that the direct relation between T1 appraisal supervisor support and T2 dealing with a heavy workload in situation 1 was significant and negative $(\beta=-1.46, p<.05)$, which indicates that more appraisal support leads to worse dealing with high workload in a team situation. Furthermore, the direct relation between $\mathrm{T} 1$ emotional supervisor support and T2 dealing with a heavy workload in situation 1 was significant and positive $(\beta=1.23, p<.05)$, which implies that more emotional
Table 4 Outcome of structural equation modelling

\begin{tabular}{|c|c|c|c|c|}
\hline & \multirow[t]{2}{*}{ Predictors } & \multirow{2}{*}{$\begin{array}{l}\text { T2 } \\
\text { Use of self-leadership } \\
\text { skills } \beta^{\text {a,b }}\end{array}$} & \multicolumn{2}{|c|}{$\mathrm{T} 2$ performance $\beta^{\mathrm{a}}$} \\
\hline & & & $\begin{array}{l}\text { Keeping } \\
\text { detached } \\
\text { concern }^{b}\end{array}$ & $\begin{array}{l}\text { Dealing } \\
\text { with a heavy } \\
\text { workload }^{\text {b }}\end{array}$ \\
\hline T1 Motivation to transfer & & $.49 * * * / .22 *$ & $.14 /-.07$ & $-.13 /-.11$ \\
\hline T1 Appraisal supervisor support & & $.13 / .16$ & $-.69 /-.34$ & $-1.46 * /-.37$ \\
\hline T1 Emotional supervisor support & & $-.09 / .05$ & $.69 / .24$ & $1.23 * / .55$ \\
\hline T2 Use of self-leadership skills & & & $.11 / .31^{*}$ & $.08 /-.12$ \\
\hline T0 Keeping detached concern & & & $.37 * * * / .33 * *$ & \\
\hline T0 Dealing with a heavy workload & & & & $.02 / .46^{* * *}$ \\
\hline$R^{2}$ & & $.26 / .11$ & $.19 / .20$ & $.26 / .25$ \\
\hline \multicolumn{5}{|l|}{$N=155$} \\
\hline \multicolumn{5}{|l|}{${ }^{*} p<.05 ; * * p<.01 ; * * * p<.001$} \\
\hline \multicolumn{5}{|c|}{${ }^{a}$ Reported for each work situation separately (S1/S2) } \\
\hline
\end{tabular}


support leads to better dealing with a high workload in the teamwork situation.

Figure 2 shows the results of the analysis. For simplicity, only the significant relations are included.

\section{Discussion}

The purpose of this study was to address the criterion problem in transfer research that states that it is important to define when or in what situation the transfer of newly learned skills should occur. We therefore included two different but highly specific and relevant job situations for our sample of crime fighters: a teamwork situation and an individual work situation. Although we expected that the trained emotional self-leadership skills would be relevant in both contexts, we nevertheless assessed whether this was indeed the case. We furthermore included three steps in the transfer process (i.e. the motivation to transfer, use of skills, and performance) to determine how and when transfer after a training occurs. Additionally, we included the effect of two types of supervisor support behaviour, namely, appraisal supervisor support and emotional supervisor support, on the initial transfer. The results of our study showed that in both work situations, the participants used emotional self-leadership skills three months after the training, and in both work situations, more motivation to transfer led to a greater use of skills. However, only in the individual situation was the use of emotional self-leadership skills related to keeping detached concern. The lack of results for the team situation may be explained by the contextual factors, such as culture, climate, politics, and social interactions (Marin-Garcia and Tomas 2016), which may be more dominant in the team situation than in the individual situation. Based on the AMO model (Appelbaum et al. 2000), we argued that ability (from the training), the motivation to transfer (after training), and the use of skills are needed for improving performance. However, contextual factors may affect the optimal and effective use of the skills in a specific context and subsequently, the outcomes (Marin-Garcia and Tomas 2016). Our findings are in line with the results from a study by Liu and Smith (2011) who found that individual endeavours to use training content during work in the child welfare sector differed from the use of skills from training in a team. Additionally, in their study on self-leadership and team members' performance, Hauschildt and Konradt (2012) found that the effect of self-leadership on team member proficiency was negatively moderated by collectivism. They suggested that highly collectivistic team members fulfil their team member role better than less collectivistic team members without the need to actively influence their self-regulation, as collectivism has been shown to predict several job performance aspects of team members (Jackson et al. 2006). Thus, in a team context, contextual factors may make it more difficult to use self-leadership skills. Additionally, high team collectivism may create a situation where employees do not feel the need to use the skills to perform and consequently do not use them.

Contrary to our expectations, supervisor behaviour directly after training was not related to the more long-term use of emotional self-leadership skills three months posttraining. However, we found support for the impact of supervisor support on performance three months posttraining. More specifically, our results suggest that emotional supervisor support may positively impact dealing with a heavy workload in the team situation. These findings are in line with the previous research that suggests that emotional support

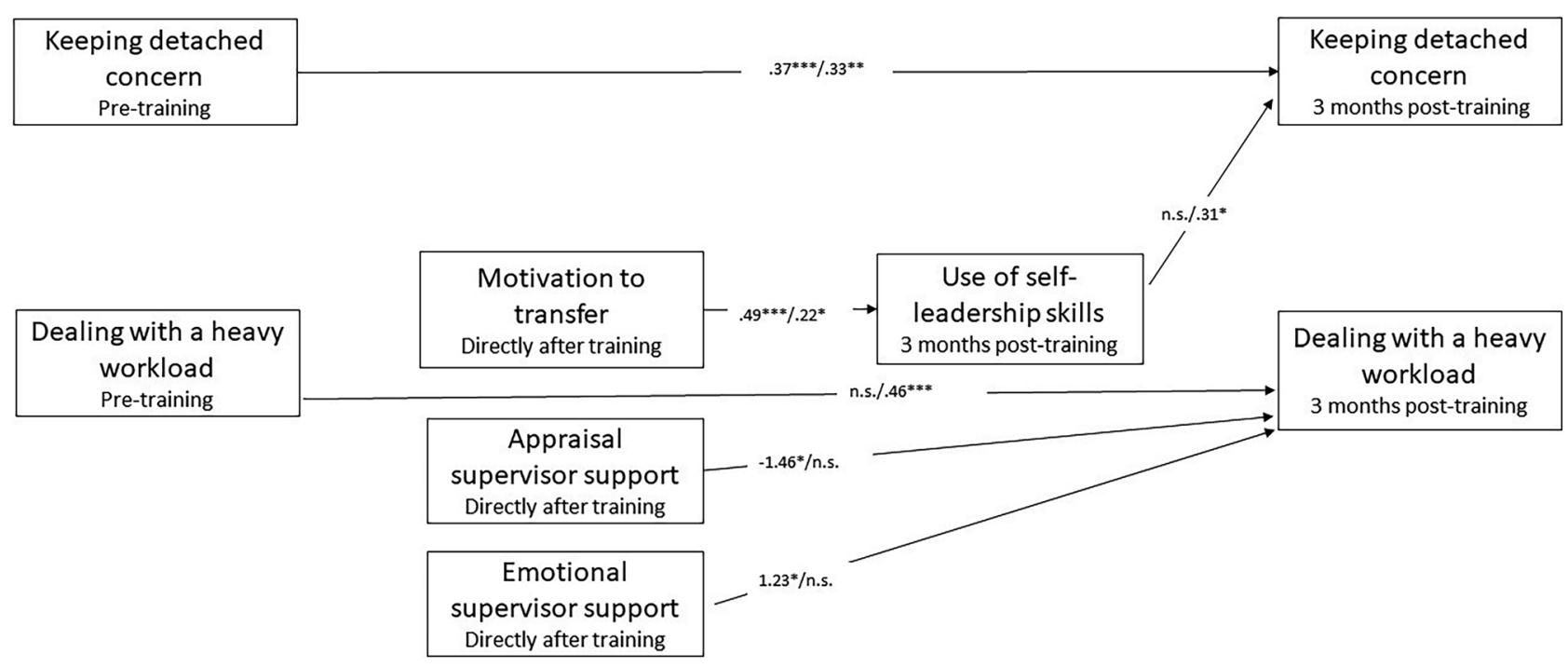

Fig. 2 Results of the analysis. Note $.26 * * / .22 * *$ refer to significant relations for situation 1/situation 2, respectively; n.s. refers to not significant effect. $* p<.05 ; * * p<.01 ; * * * p<.001$ 
provides training participants with a feeling that supervisors care about them and value their contribution to work outcomes. Based on social exchange theory (Blau 1964) and perceived organisational support (Eisenberger et al. 1986), several authors have argued that this affective attachment is positively related to individual work outcomes (Golden and Veiga 2008; Knies and Leisink 2014) and relieves the effects of work-related stress (Eschleman 2011; Suan and Nasurdin 2016). At the team level, the effect of emotional supervisor support may be even stronger because interactions between team members give rise to the collective perception of supervisor support through repeated cycles of individual interactions and influence (Pohl and Galletta 2017).

Additionally, our results indicate that appraisal supervisor support after training may negatively impact dealing with a heavy workload in the team situation. Thus, more relationalfocused emotional supervisor support has a positive effect on dealing with a heavy workload, and more performancefocused appraisal supervisor support has a negative effect on dealing with a heavy workload. This may be explained by the training participants' attributions of supervisor support (Eschleman 2011). The high altruistic and low self-serving intent of emotional supervisor support may lead to improved job attitudes (Eschleman 2011), whereas the behavioural reaction of the supervisor (i.e. appraisal support) may give employees the feeling that they are incompetent or unwanted (Beehr et al. 2010) and consequently may negatively affect performance.

With these findings, we make several important contributions. First, our study demonstrates that it is useful to include the motivation to transfer, use of skills, and performance as separate steps in the transfer process to obtain a better view of how and why transfer occurs in a specific situation. We found that the motivation to transfer alone does not explain the transfer results because in our study, the same level of motivation to transfer led to different levels of the use of trained skills for situations 1 and 2, and the motivation to transfer was not directly related to performance. Similarly, the use of trained skills at work alone does not explain the transfer results because the use of self-leadership was only related to performance in the individual situation, not in the team situation. Second, our study demonstrates that it is important to be clear about what is expected to change as a function of the training. Many transfer studies measure the use of skill (e.g. Ladyshewsky and Flavell 2012; Stenling and Tafvelin 2016) or ask general questions about how the use of skills from the training improved work (e.g. Millar and Stevens 2012; Simosi 2012; Xiao 1996). We expected that the emotional self-leadership skills from the training would lead to increased performance in the individual and team situations. Our study shows that skills may be used less in one situation than in another situation, for example, because they are less needed or more difficult to use. Consequently, performance results may not occur or may take more time to occur. Additionally, the use of skills may lead to less performance in one situation compared to another because barriers in the context may moderate the effect of the use of skills on performance. Our study suggests that asking about the use of skills per work situation and asking about specific performance per work situation led to a more nuanced picture of the posttraining transfer process. Such a more nuanced picture may help organisations improve transfer and ensure that the skills from training are used where they are needed the most. Third, our study identifies the importance of differentiating supervisor behaviours during transfer. Our finding underscores the previous transfer research that asserts that supervisor support is a multidimensional construct and that differential effects can be expected (Govaerts 2017; Schindler and Burkholder 2016) based on subordinate attributions of supervisor support. Although supervisor support behaviour is often helpful for transfer, the work context in which the support is provided can result in the support behaviour becoming a stressor rather than a resource for the employee. Consequently, such supervisor support behaviour may negatively impact transfer (Eschleman 2011).

\section{Limitations and Suggestions for Further Research}

Some study limitations should be acknowledged. First, all of the data were self-reported and may be biased by the perceptions of the respondents, which could have caused an underestimation of the performance results. Terborg et al. (1980) mention several problems that arise when preand post-self-report data are used as criteria in, for example, leadership training. The observed differences between pre- and postintervention measures may reflect an unknown amount of true change and an unknown amount of change due to instrumentation. Before the training, the training participants rated their performance based on the performance standards that they experienced at this moment. If they rate their performance three months posttraining, then they might provide a lower score for their performance even when it improved because they experienced the performance standard in a different way. Further research could therefore benefit from a larger sample and a control group to ensure that the observed changes are due to training rather than to other environmental or organisational influences.

Although the use of self-reported measures may lead to common method bias (Podsakoff et al. 2012), self-reported data also have advantages and are well suited to study employees' perceptions, behavioural intentions, or perceived job changes (Spector, 1994), especially when other data sources are absent. Moreover, self-reported data minimise disturbances in the field while giving a good indication of 
the associations among the different variables under study, especially in longitudinal studies (Spector, 1994). This is important, given the difficulty of obtaining information and cooperation from respondents in companies for multi-wave research. Additionally, we took appropriate precautions in the survey design and during data analysis to mitigate some concerns regarding common method bias, such as promising anonymity and separating predictors and outcomes in the questionnaire. Finally, since detached concern and dealing with heavy workload efficacy are psychological states of individuals, which are difficult for others to observe, selfratings can be assumed to be appropriate measures that are more reflective of reality than supervisor ratings or observations by others (Lampert et al. 2019).

Second, in this study, we focused on the impact of the motivation to transfer and supervisor support behaviours on transfer. However, other pre- and posttraining variables can contribute to transfer. Pretraining factors that are related to motivational states after training and actual transfer include perceptions of the programme (Gegenfurtner et al. 2009) and the motivation to learn (Gegenfurtner and Vauras 2012; Grossman and Salas 2011). Posttraining factors that are found to be related to transfer include autonomy (Axtell et al. 1997), the organisational learning culture (Martin 2010; RichmanHirsch 2001; Tracey et al. 1995) and peer support (Antle et al. 2008; Chiaburu et al. 2010; Massenberg et al. 2017). Such variables may impact the use of skills and performance results. Since our findings indicate that the social context may impact transfer results in a specific situation, further research may benefit from including factors related to this context, such as autonomy, the organisational learning culture, and peer support. In case a transfer will take place in a team context (cf. our first work situation), factors related to the team situation, such as collectivism (Jackson et al. 2006) and team efficacy (Cannon-Bowers et al. 2003), could be included in future research to obtain a better view of the transfer process and the factors that influence this collective transfer process.

Third, future research would benefit from a more specific measure of supervisor behaviour to obtain a better understanding of the role of specific supervisor behaviour during transfer. In general, supervisor support can be described as the extent to which supervisors enable or stimulate the use of trained skills during work (Holton et al. 2000). Many transfer studies use a nonspecific measure for supervisor support. For example, the subscale for supervisor support often used from the Learning Transfer System Inventory (LTSI) by Holton III (2005) asks more general questions such as "Did your supervisor support you on the use of trained skills?". In the current study, we used Nijman's more specific conceptualisation of supervisor support (Nijman 2004). He distinguished four different types of supervisor support from which we used the two best that were applicable in our specific study, namely, posttraining appraisal supervisor support and posttraining emotional supervisor support. However, over recent decades, supervisor support during transfer has referred to a range of actions, such as coaching (e.g. Hutchins et al. 2013a, b), discussing application (e.g. Chiaburu et al. 2010), encouragement (e.g. Al-Eisa et al. 2009), providing opportunities to practice (e.g. Facteau et al. 1995), providing practical support (e.g. Gregoire et al. 1998), and providing rewards (e.g. Velada et al. 2007). For further research, these various actions argue for a measure of supervisor support that reflects the specific and concrete behaviours of the supervisor. For example, Govaerts (2017) presents a 41-item scale for supervisor support behaviour that consists of nine dimensions, specifically, pretraining information, role modelling and facilitation, favourable attitude, request sharing, openness, coaching and feedback, involvement and accountability, work coverage, and training participation. Our measure on emotional supervisor support fits in Govaerts' "openness", which focuses on the supervisors' attitude ("being open to new ideas and change, and accept that training participants may make mistakes when they try to apply the training programme in their job" (Govaerts 2017, p. 120)). Our measure on appraisal supervisor support would fit in Govaerts' measure on "coaching and feedback", which refers to "supervisor behaviour regarding coaching employees in applying newly learned competences at work, and providing feedback on the training application and work performance in general" (Govaerts 2017, p. 120). This new set of supervisor behaviours - Govaerts' publication was not yet available when we started our study - may lead to a better overview of the areas in supervision support during transfer that deserve more attention. Finally, this study only focused on supervisor support at the initial stage of the transfer process. The complexity of the transfer process demands further examination of how supervisor support behaviours influence each of the stages of the transfer process.

\section{Conclusions and Practical Implications}

A major gap in the research on the transfer of training is a profound overview of stages in the posttraining transfer process and a focus on the actual context in which transfer occurs and how it occurs (cf. Baldwin et al. 2017). This study demonstrates that specifying the transfer stages and work situation in which transfer occurs is important to obtain a realistic view of the transfer process. Based on our study, some practical advice can be provided. First, organisations should realise that transfer results may differ according to the work situation. If they want to check if the skills are effectively used in the expected situation, then organisations should be explicit about what behaviour or performance in what specific work situation should change as a result of the training. Using a nonspecific measure may lead to an overly optimistic view (skills may be 
used in another, less contributing situation) or even a misleading view (skills are used in a situation where they should not be used, i.e. negative transfer; Zubairy, Mozie and Ghazali 2015) on transfer. Second, the motivation to transfer is important to start using skills from the training. Checking directly after training if participants are motivated to transfer skills to the work context may pinpoint a lack of such motivation and enable organisations to add information on content relevance (Kirwan and Birchall 2006; Liebermann and Hoffmann 2008) or provide additional transfer-enhancing interventions (Blume et al. 2010; Sookhai and Budworth 2010) to increase the motivation to transfer. Third, supervisor behaviour is related to transfer (Nijman et al. 2006; Nijman and Gelissen 2011). Although we did not find support for the effect of different supervisor behaviours on the use of skills, our research suggests that appraisal supervisor support and emotional supervisor support are related to dealing with a heavy workload in a team situation. Supervisors are often not aware of their role during transfer (Lancaster et al. 2013), and making them aware of the effect of their behaviour on learning and transfer in the organisation can be a first step to improving transfer.

Author Contribution All authors contributed to the conceptualization and design of the study. Material preparation, data collection and analysis were conducted by the first author. All authors wrote and approved the final manuscript.

Data Availability The data that support the findings of this study are available from the Dutch Police. Restrictions apply to the availability of these data, which were used under license for this study.

\section{Declarations}

Ethics Approval This study was performed in line with the principles of the Declaration of Helsinki. Approval was granted by the Management of the Dutch Police (10-04-2015; KNP15000613).

Conflict of Interest The authors declare no competing interests.

Open Access This article is licensed under a Creative Commons Attribution 4.0 International License, which permits use, sharing, adaptation, distribution and reproduction in any medium or format, as long as you give appropriate credit to the original author(s) and the source, provide a link to the Creative Commons licence, and indicate if changes were made. The images or other third party material in this article are included in the article's Creative Commons licence, unless indicated otherwise in a credit line to the material. If material is not included in the article's Creative Commons licence and your intended use is not permitted by statutory regulation or exceeds the permitted use, you will need to obtain permission directly from the copyright holder. To view a copy of this licence, visit http://creativecommons.org/licenses/by/4.0/.

\section{References}

Adang O (2012) Police organization and training. In M. R. Haberfeld and A. Von Hassell (eds.) Police organization and training: innovations in research and practice (pp. 191-205). Springer Science+Business Media. https://doi.org/10.1007/978-1-4614-0745-4

Al-Eisa AS, Furayyan MA, Alhemoud AM (2009) An empirical examination of the effects of self-efficacy, supervisor support and motivation to learn on transfer intention. Manag Decis 47(8):12211244. https://doi.org/10.1108/00251740910984514

Antle BF, Barbee AP, Van Zyl MA (2008) A comprehensive model for child welfare training evaluation. Child Youth Serv Rev 30(9):1063-1080. https://doi.org/10.1016/j.childyouth.2008. 02.002

Anton NE, Beane J, Yurco AM, Howley LD, Bean E, Myers EM, Stefanidis D (2018) Mental skills training effectively minimizes operative performance deterioration under stressful conditions: results of a randomized controlled study. Am J Surg 215(2):214-221. https://doi.org/10.1016/j.amjsurg.2017.09.039

Appelbaum E, Bailey T, Berg P, Kalleberg AL, Bailey TA (2000) Manufacturing competitive advantage: the effects of high performance work systems on plant performance and company outcomes. Cornell University Press

Arnetz BB (2012) Assessment of a prevention program for workrelated stress among urban police officers. Int Arch Occup Environ Health 29(6):997-1003. https://doi.org/10.1016/j.biotechadv. 2011.08.021.Secreted

Arnetz BB, Nevedal DC, Lumley MA, Backman L, Lublin A (2009) Trauma resilience training for police: psychophysiological and performance effects. J Police Crim Psychol 24(1):1-9. https:// doi.org/10.1007/s11896-008-9030-y

Axtell CM, Maitlis S, Yearta SK (1997) Predicting immediate and longer-term transfer of training. Pers Rev 26(3):201-213. https:// doi.org/10.1108/00483489710161413

Baldwin TT, Ford JK, Blume BD (2017) The state of transfer of training research: moving toward more consumer-centric inquiry. Hum Resour Dev Q 28(1):17-28. https://doi.org/10.1002/hrdq. 21278

Bandura A (1986) Social foundations of thought and action: a socialcognitive view. Prentice Hall

Barnett SM, Ceci SJ (2002) When and where do we apply what we learn? A taxonomy for far transfer. Psychol Bull 128(4):612-637. https://doi.org/10.1037/0033-2909.128.4.612

Beehr TA, Bowling NA, Bennett MM (2010) Occupational stress and failures of social support: when helping hurts. J Occup Health Psychol 15(1):45. https://doi.org/10.1037/a0018234

Berking M, Meier C, Wupperman P (2010) Enhancing emotion-regulation skills in police officers: results of a pilot controlled study. Behav Ther 41(3):329-339. https://doi.org/10.1016/j.beth.2009.08.001

Blau PM (1964) Exchange and power in social life. Wiley

Blume BD, Ford JK, Baldwin TT, Huang JL (2010) Transfer of training: a meta-analytic review. J Manag 36(4):1065-1105. https:// doi.org/10.1177/0149206309352880

Botke J, Jansen P, Khapova S, Tims M (2018) Work factors influencing the transfer stages of soft skills training: a literature review. Educ Res Rev 24(March):130-147. https://doi.org/10.1016/j.edurev. 2018.04.001

Brown TC, Warren AM (2009) Distal goal and proximal goal transfer of training interventions in an executive education program. Hum Resour Dev Q 20(3):265-284. https://doi.org/10.1002/hrdq. 20021

Browne MW, Cudeck R (1992) Alternative ways of assessing model fit. Sociological Methods \& Research 21(2):230-258. https://doi. org/10.1177/0049124192021002005 
Burke LA, Hutchins HM (2007) Training transfer: an integrative literature review. Hum Resour Dev Rev 6(3):263-296. https://doi. org/10.1177/1534484307303035

Cannon-Bowers JA, Salas E, Milham LM (2003) The transfer of team training. In: Holton EF, Baldwin TT (eds) Improving learning transfer in organizations. Jossey-Bass, San Francisco, pp 195-223

Cheng EWL, Hampson I (2008) Transfer of training: a review and new insights. Int J Manag Rev 10(4):327-341. https://doi.org/ 10.1111/j.1468-2370.2007.00230.x

Chiaburu DS, Van Dam K, Hutchins H (2010) Social support in the workplace and training transfer: a longitudinal analysis. Int $\mathbf{J}$ Sel Assess 18(2):187-200. https://doi.org/10.1111/j.1468-2389. 2010.00500.x

Chiorri C, Garbarino S, Bracco F, Magnavita N (2015) Personality traits moderate the effect of workload sources on perceived workload in flying column police officers. Front Psychol 6(1835). https://doi.org/10.3389/fpsyg.2015.01835

Cohen S, Underwood LG, Gottlieb BH (2000) Social support measurement and intervention: a guide for health and social scientists. Oxford University Press. https://doi.org/10.1093/med:psych/ 9780195126709.001.0001

Colquitt JA, LePine JA, Noe RA (2000) Toward an integrative theory of training motivation: a meta-analytic path analysis of 20 years of research. J Appl Psychol 85:678-707. https://doi.org/10.1037// 0021-9010.85.5.678

De Grip A, Sauermann J (2013) The effect of training on productivity: the transfer of on-the-job training from the perspective of economics. Educ Res Rev 8(January):28-36. https://doi.org/10. 1016/j.edurev.2012.05.005

Decety J, Smith KE, Norman GJ, Halpern J (2014) A social neuroscience perspective on clinical empathy. World Psychiatry 13(3):233-237. https://doi.org/10.1002/wps.20146

Delahaij R, Kamphuis W, Venrooij W (2014) Weerbaarheidsmonitor en dashboard - Familierechercheurs(TNO 2014 M11034). TNO

Dolbier CL, Soderstrom M, Steinhardt MA (2001) The relationships between self-leadership and enhanced psychological, health, and work outcomes. J Psychol 135(5):469-485. https://doi.org/10. 1080/00223980109603713

Dormann C, Zapf D (2004) Customer-related social stressors and burnout. J Occup Health Psychol 9(1):61-82. https://doi.org/10.1037/ 1076-8998.9.1.61

Efklides A, Kourkoulou A, Mitsiou F, Ziliaskopoulou D (2006) Metacognitive knowledge of effort, personality factors, and mood state: their relationships with effort-related metacognitive experiences. Metacogn Learn 1(1):33-49. https://doi.org/10.1007/ s11409-006-6581-0

Eisenberger R, Huntington R, Hutchison S, Sowa D (1986) Perceived organizational support. J Appl Psychol 71(3):500-507. https:// doi.org/10.1037/0021-9010.71.3.500

Eschleman K (2011) The effects of causal attributions on subordinate responses to supervisor support (unpublished doctoral study) [Wright State University]. http://rave.ohiolink.edu/etdc/view? acc_num=wright 1310416190

Facteau JD, Dobbins GH, Russell JEA, Ladd RT, Kudisch JD (1995) Influence of general perceptions of the training environment on pretraining motivation and perceived training transfer. J Manag 21(1):1-25. https://doi.org/10.1177/014920639502100101

Ford JK (1997) Transfer of training: the criterion problem. Appl Psychol 46(4):349-354. https://doi.org/10.1111/j.1464-0597.1997. tb01237.x

Foxon M (1993) A process approach to the transfer of training. Part 1: the impact of motivation and supervisor support on transfer maintenance. Aust J Educ Technol 9(2):130-143. https://doi.org/ 10.14742/ajet.2104
Fredrickson BL (2004) The broaden-and-build theory of positive emotions. Philosophical Transactions of the Royal Society B: Biological Sciences 359(1449):1367-1377. https://doi.org/10.1098/rstb.2004.1512

Gegenfurtner A (2011) Motivation and transfer in professional training: a meta-analysis of the moderating effects of knowledge type, instruction, and assessment conditions. Educ Res Rev 6(3):153168. https://doi.org/10.1016/j.edurev.2011.04.001

Gegenfurtner A (2013) Dimensions of motivation to transfer: a longitudinal analysis of their influence on retention, transfer, and attitude change. Vocat Learn 6(2):187-205. https://doi.org/10. 1007/s12186-012-9084-y

Gegenfurtner A, Vauras M (2012) Age-related differences in the relation between motivation to learn and transfer of training in adult continuing education. Contemp Educ Psychol 37:33-46. https:// doi.org/10.1016/j.cedpsych.2011.09.003

Gegenfurtner A, Veermans K, Festner D, Gruber H (2009) Motivation to transfer training: an integrative literature review. Hum Resour Dev Rev 8(3):403-423. https://doi.org/10.1177/ 1534484309335970

Golden TD, Veiga JF (2008) The impact of superior-subordinate relationships on the commitment, job satisfaction, and performance of virtual workers. Leadersh Quart 19(1):77-88. https://doi.org/ 10.1016/j.leaqua.2007.12.009

Goldsby E, Goldsby M, Neck CB, Neck CP (2020) Under pressure: time management, self-leadership, and the nurse manager. Administrative Sciences 10(3):38. https://doi.org/10.3390/ admsci 10030038

Govaerts N (2017) Transfer of training in corporate settings: toward an understanding of the multidimensional role of the supervisor (unpublished doctoral study). KU Leuven, Belgium

Govaerts N, Dochy F (2014) Disentangling the role of the supervisor in transfer of training. Educ Res Rev 12(June):77-93. https://doi. org/10.1016/j.edurev.2014.05.002

Govaerts N, Kyndt E, Dochy F (2017a) The influence of specific supervisor support types on transfer of training: examining the mediating effect of training retention. Vocat Learn 11(2):1-24. https:// doi.org/10.1007/s12186-017-9190-y

Govaerts N, Kyndt E, Vreye S, Dochy F (2017b) A supervisors' perspective on their role in transfer of training. Hum Resour Dev Q 28(4):515-552. https://doi.org/10.1002/hrdq.21286

Gregoire TK, Propp J, Poertner J (1998) The supervisor's role in the transfer of training. Adm Soc Work 22(1):1-18. https://doi.org/ 10.1300/J147v22n01_01

Grossman R, Burke-Smalley LA (2018) Context-dependent accountability strategies to improve the transfer of training: a proposed theoretical model and research propositions. Hum Resour Manag Rev 28(2):234-247. https://doi.org/10.1016/j.hrmr.2017.08.001

Grossman R, Salas E (2011) The transfer of training: what really matters. Int J Train Dev 15(2):103-120. https://doi.org/10.1111/j. 1468-2419.2011.00373.x

Hart SG, Staveland LE (1988) Development of NASA-TLX (Task Load Index): results of empirical and theoretical research. Adv Psychol 52:139-183. https://doi.org/10.1016/S0166-4115(08)62386-9

Hauschildt K, Konradt U (2012) Self-leadership and team members' work role performance. J Manag Psychol 27(5):497-517. https:// doi.org/10.1108/02683941211235409

Holton EF III (2005) Holton's evaluation model: new evidence and construct elaborations. Adv Dev Hum Resour 7(1):37-54. https:// doi.org/10.1177/1523422304272080

Holton EF III, Bates RA, Ruona WEA (2000) Development of a generalized learning transfer system inventory. Hum Resour Dev Q 11(4):333-360. https://doi.org/10.1002/1532-1096(200024) 11:4\%3c361::AID-HRDQ3\%3e3.0.CO;2-F

Hooper D, Coughlan J, Mullen MR (2008) Structural equation modelling: guidelines for determining model fit. The Electronic Journal of Business Research Methods 6(1):53-60 
Houghton JD, Neck CP (2002) The revised self-leadership questionnaire:Testing a hierarchical factor structure for selfleadership. J Manag Psychol 17(8):672-691. https://doi.org/10. $1108 / 02683940210450484$

House JS (1981) Work stress and social support. Addison-Wesley

Hu L, Bentler P (1999) Cutoff criteria for fit indexes in covariance structure analysis: Conventional criteria versus new alternatives. Struct Equ Modeling 6(1):1-55. https://doi.org/10.1080/ 10705519909540118

Huang JL, Blume BD, Ford JK, Baldwin TT (2015). A tale of two transfers: Disentangling maximum and typical transfer and their respective predictors. J Bus Psychol 30(4):709-732. https://doi.org/10.1007/s10869-014-9394-1

Huijs JJJM, Houtman ILD, Kallen VL (2014) Langdurig verzuim bij de Nederlandse politie (No. TNO 2014 R14079). http:// repository.tudelft.nl/view/tno/uuid:a1f83bfd-31cc-4d6d-b27fe0af2d15aa57/

Huisman S, Princen M, Klerks P, Kop N (2016) Handelen naar waarheid (Internal report). Politieacademie Apeldoorn

Hutchins HM, Nimon K, Bates R, Holton E (2013a) Can the LTSI predict transfer performance? Testing intent to transfer as a proximal transfer of training outcome. Int J Sel Assess 21(3):251-263. https://doi.org/10.1111/ijsa.12035

Hutchins SD, Wickens CD, Carolan TF, Cumming JM (2013b) The influence of cognitive load on transfer with error prevention training methods: a meta-analysis. Hum Factors 55:854-874. https://doi.org/10.1177/0018720812469985

Jackson CL, Colquitt JA, Wesson MJ, Zapata-Phelan CP (2006) Psychological collectivism: a measurement validation and linkage to group member performance. J Appl Psychol 91(4):884-899. https://doi.org/10.1037/0021-9010.91.4.884

Janssens KME, van der Velden PG, Taris R, van Veldhoven MJPM (2021) Resilience among police officers: a critical systematic review of used concepts, measures, and predictive values of resilience. J Police Crim Psychol 36(1):24-40. https://doi.org/ 10.1007/s11896-018-9298-5

Karssiens AEA, Van der Linden C, Wilderom CPM, Furtmueller E (2014) Embodied mind knowledge in leadership practice: creating space in patterned thoughts and behaviors. J Manag Inq 23(3):231-241. https://doi.org/10.1177/1056492613513501

Kirwan C (2009) Improving learning transfer: a guide to getting more out of what you put into your training. Gower Publishing, Ltd. https://doi.org/10.4324/9781315588063

Kirwan C, Birchall D (2006) Transfer of learning from management development programmes: testing the Holton model. Int J Train Dev 10(4):252-268. https://doi.org/10.1111/j.1468-2419.2006. 00259.x

Knies E, Leisink P (2014) Linking people management and extra-role behaviour: results of a longitudinal study. Hum Resour Manag J 24(1):57-76. https://doi.org/10.1111/1748-8583.12023

Krosnick J (1999) Survey research. Annu Rev Psychol 50:537-567. https://doi.org/10.4018/978-1-4666-7409-7.ch020

Ladyshewsky RK, Flavell H (2012) Transfer of training in an academic leadership development program for program coordinators. Educational Management Administration \& Leadership 40(1):127147. https://doi.org/10.1177/1741143211420615

Laker DR (1990) Dual dimensionality of training transfer. Hum Resour Dev Q 1(3):209-223. https://doi.org/10.1002/hrdq. 3920010303

Lampert B, Glaser J (2018) Detached concern in client interaction and burnout. Int J Stress Manag 25(2):129-143. https://doi.org/10. 1037/str0000053

Lampert B, Unterrainer C, Seubert CT (2019) Exhausted through client interaction-detached concern profiles as an emotional resource over time? PLoS One 14(5):1-20. https://doi.org/10.1371/ journal.pone.0216031
Lancaster S, Di Milia L, Cameron R (2013) Supervisor behaviours that facilitate training transfer. J Work Learn 25(1):6-22. https://doi. org/10.1108/13665621311288458

Le Scanff C, Taugis J (2002) Stress management for police special forces. J Appl Sport Psychol 14(4):330-343. https://doi.org/10. 1080/10413200290103590

Lee C, Lee H, Lee J, Park J (2014) A multiple group analysis of the training transfer model: exploring the differences between high and low performers in a Korean insurance company. Int J Hum Resour Manag 25(20):2837-2857. https://doi.org/10.1080/ 09585192.2014 .934887

Liebermann S, Hoffmann S (2008) The impact of practical relevance on training transfer: evidence from a service quality training program for German bank clerks. Int J Train Dev 12(2):74-86. https://doi.org/10.1111/j.1468-2419.2008.00296.x

Liu JQ, Smith BD (2011) Transferring training to child welfare practice: individual and collective efforts. Child Youth Serv Rev 33:149-156. https://doi.org/10.1016/j.childyouth.2010.08.027

Lovelace KJ, Manz CC, Alves JC (2007) Work stress and leadership development: the role of self-leadership, shared leadership, physical fitness and flow in managing demands and increasing job control. Hum Resour Manag Rev 17(4):374-387. https://doi. org/10.1016/j.hrmr.2007.08.001

Malhotra MK, Sharma S (2008) Measurement equivalence using generalizability theory: an examination of manufacturing flexibility dimensions. Decis Sci 39(4):643-669. https://doi.org/10.1002/ 9780470373699.speced0894

Manz CC (1986) Self-leadership: toward an expanded theory of self-influence processes in organizations. Acad Manag Rev 11(3):585-600. https://doi.org/10.5465/amr.1986.4306232

Manz CC (2015) Taking the self-leadership high road: smooth surface or potholes ahead? Acad Manag Perspect 29(1):132-151. https:// doi.org/10.5465/amp.2013.0060

Manz CC, Houghton JD, Neck CP, Fugate M, Pearce C (2016) Whistle while you work: toward a model of emotional self-leadership. J Leadersh Org Stud 23(4):374-386. https://doi.org/10.1177/ 1548051816655993

Marin-Garcia JA, Tomas JM (2016) Deconstructing AMO framework: a systematic review. Intangible Capital 12(4):1040-1087. https:// doi.org/10.3926/ic.838

Marques-Quinteiro P, Curral LA (2012) Goal orientation and work role performance: Predicting adaptive and proactive work role performance through self-leadership strategies. J Psychol: Interdiscip Appl 146(6):559-577. https://doi.org/10.1080/00223980. 2012.656157

Martin HJ (2010) Workplace climate and peer support as determinants of training transfer. Hum Resour Dev Q 21(1):87-104. https:// doi.org/10.1002/hrdq.20038

Massenberg AC, Schulte EM, Kauffeld S (2017) Never too early: learning transfer system factors affecting motivation to transfer before and after training programs. Hum Resour Dev Q 28(1):55-85. https://doi.org/10.1002/hrdq

Massenberg AC, Spurk D, Kauffeld S (2015) Social support at the workplace, motivation to transfer and training transfer: a multilevel indirect effects model. Int J Train Dev 19(3):161-178. https://doi.org/10.1111/ijtd.12054

Millar P, Stevens J (2012) Management training and national sport organization managers: examining the impact of training on individual and organizational performances. Sport Management Review 15(3):288-303. https://doi.org/10.1016/j.smr.2012.01. 003

Neck CP, Houghton JD (2006) Two decades of self-leadership theory and research: past developments, present trends, and future possibilities. J Manag Psychol 21(4):270-295. https://doi.org/10. 1108/02683940610663097 
Neck CP, Manz CC (2016) Thought Self-Leadership: The Influence of Self-Talk and Mental Imagery on Performance. J Organ Behav 13(7):681-699. https://doi.org/10.1002/job.4030130705

Neck CP, Houghton JD, Sardeshmukh SR, Goldsby M, Godwin JL (2013) Self-leadership: a cognitive resource for entrepreneurs. J Small Bus Entrep 26(5):463-480. https://doi.org/10.1080/ 08276331.2013 .876762

Nesbit PL (2012) The role of self-reflection, emotional management of feedback, and self-regulation processes in self-directed leadership development. Hum Resour Dev Rev 11(2):203-226. https:// doi.org/10.1177/1534484312439196

$\mathrm{Ng} \mathrm{KH} \mathrm{(2015)} \mathrm{Supervisory} \mathrm{practices} \mathrm{and} \mathrm{training} \mathrm{transfer:} \mathrm{lessons} \mathrm{from}$ Malaysia. Asia Pac J Hum Resour 53(2):221-240. https://doi.org/ 10.1111/1744-7941.12044

Nijman D-JJM (2004) Supporting transfer of training: effects of the supervisor (unpublished doctoral study) [University of Twente, The Netherlands]. http://doc.utwente.nl/76049/

Nijman D-JJM, Gelissen J (2011) Direct and indirect effects of supervisor support on transfer of training. In RF Poell and M Van Woerkom (eds.) Supporting Workplace Learning (pp. 89-106). Springer Science+Business Media B.V. https://doi.org/10.1007/ 978-90-481-9109-3

Nijman D-JJM, Nijhof WJ, Wognum AAM, Veldkamp BP (2006) Exploring differential effects of supervisor support on transfer of training. J Eur Ind Train 30(7):529-549. https://doi.org/10. 1108/03090590610704394

Nikolova I, Van Ruysseveldt J, De Witte H, Van Dam K (2014) Learning climate scale: construction, reliability and initial validity evidence. J Vocat Behav 85(3):258-265. https://doi.org/10.1016/j. jvb.2014.07.007

Oron-Gilad T, Szalma JL, Stafford SC, Hancock PA (2008) The workload and performance relationship in the real world: a study of police officers in a field shooting exercise. Int J Occup Saf Ergon 14(2):119-131. https://doi.org/10.1080/10803548.2008. 11076757

Parker SK, Bindl UK, Strauss K (2010) Making things happen: a model of proactive motivation. J Manag 36(4):827-856. https:// doi.org/10.1177/0149206310363732

Patterson GT, Chung IW, Swan PG (2012) The effects of stress management interventions among police officers and recruits. The Campbell Collaboration 8(1):1-53. https://doi.org/10.4073/csr. 2012.7

Podsakoff PM, MacKenzie SB, Podsakoff NP (2012) Sources of method bias in social science research and recommendations on how to control it. Annu Rev Psychol 63(1):539-569. https://doi. org/10.1146/annurev-psych-120710-100452

Pohl S, Galletta M (2017) The role of supervisor emotional support on individual job satisfaction: a multilevel analysis. Appl Nurs Res 33:61-66. https://doi.org/10.1016/j.apnr.2016.10.004

Politie (n.d.). De cijfers van 2019. https://www.politie.nl/binaries/ content/assets/politie/nieuws/2020/infographic-politiecijfers2019-150-dpi.pdf

Rhoades L, Eisenberger R (2002) Perceived organizational support: a review of the literature. J Appl Psychol 87(4):698-714. https:// doi.org/10.1037/0021-9010.87.4.698

Richman-Hirsch WL (2001) Posttraining interventions to enhance transfer: the moderating effects of work environments. Hum Resour Dev Q 12(2):105-120. https://doi.org/10.1002/hrdq.2.abs

Russ-Eft D (2002) A typology of training design and work environment factors affecting workplace learning and transfer. Hum Resour Dev Rev 1(1):45-65. https://doi.org/10.1177/1534484302011003

Saks AM, Salas E, Lewis P (2014) The transfer of training. Int J Train Dev 18(2):81-83. https://doi.org/10.1111/ijtd.12032

Salar M, Capanoglu MF, Sherman A, Sesek RF, Davis J (2017) Training related risk factors of firefighters. Proceedings of the Human
Factors and Ergonomics Society 1844-1847. https://doi.org/10. $1177 / 1541931213601941$

Schindler LA, Burkholder GJ (2016) A mixed methods examination of the influence of dimensions of support on training transfer. J Mixed Methods Res 10(3):292-310. https://doi.org/10.1177/ 1558689814557132

Schmidt KH, Diestel S (2015) Self-control demands: from basic research to job-related applications. J Pers Psychol 14(1):49. https://doi.org/10.1111/j.1464-0597.2011.00479.x

Shahin A, Salehzadeh R (2013) Investigating the relationship among self-leadership strategies by association rules mining. International Journal of Business Information Systems 14(1):41-55. https://doi.org/10.1504/IJBIS.2013.055546

Simosi M (2012) The moderating role of self-efficacy in the organizational culture-training transfer relationship. Int J Train Dev 16(2):92-106. https://doi.org/10.1111/j.1468-2419.2011.00396.x

Sookhai F, Budworth MH (2010) The trainee in context: examining the relationship between self-efficacy and transfer climate for transfer of training. Hum Resour Dev Q 21(3):257-272. https:// doi.org/10.1002/hrdq.20044

Sparr JL, Knipfer K, Willems F (2017) How leaders can get the most out of formal training: the significance of feedback-seeking and reflection as informal learning behaviors. Hum Resour Dev Q 28(1):29-54. https://doi.org/10.1002/hrdq.21263

Spector PE (1994) Using Self-Report Questionnaires in OB Research: A Comment on the Use of a Controversial Method. J Organ Behav 15(5):385-392. https://doi.org/10.1002/job.4030150503

Stenling A, Tafvelin S (2016) Transfer of training after an organizational intervention in Swedish sports clubs: a self-determination theory perspective. J Sport Exerc Psychol 38(5):493-504. https:// doi.org/10.1123/jsep.2016-0084

Suan CL, Nasurdin AM (2016) Supervisor support and work engagement of hotel employees in Malaysia: is it different for men and women? Gender in Management 31(1):2-18. https://doi.org/10. 1108/GM-11-2014-0105

Tehseen S, Ramayah T, Sajilan S (2017) Testing and controlling for common method variance: a review of available methods. J Manag Sci 4(2):142-168. https://doi.org/10.20547/jms.2014. 1704202

Terborg JR, Howard GS, Maxwell SE (1980) Evaluating planned organizational change: a method for assessing alpha, beta, and gamma change. Acad Manag Rev 5(1):109-121. https://doi.org/ 10.5465/amr.1980.4288933

Tracey JB, Tannenbaum SI, Kavanagh MJ (1995) Applying trained skills on the job: the importance of the work environment. J Appl Psychol 80(2):239-252. https://doi.org/10.1037//0021-9010. 80.2.239

Tuleja EA, Roberts E (2011) An analysis of a communication training program for Chinese managers. IEEE Trans Prof Commun 54(2):185-200. https://doi.org/10.1109/tpc.2011.2121730

Unsworth KL, Mason CM (2012) Help yourself: the mechanisms through which a self-leadership intervention influences strain. J Occup Health Psychol 17(2):235-245. https://doi.org/10.1037/ a0026857

Van den Bossche P, Segers M, Jansen N (2010) Transfer of training: the role of feedback in supportive social networks. Int J Train Dev 14(2):81-94. https://doi.org/10.1111/j.1468-2419.2010.00343.x

Van der Locht M, Van Dam K, Chiaburu D (2013) Getting the most of management training: the role of identical elements for training transfer. Pers Rev 42(4):422-439. https://doi.org/10.1108/ PR-05-2011-0072

Van Gelderen BR, Bakker AB, Konijn E, Binnewies C (2014) Daily deliberative dissonance acting among police officers. J Manag Psychol 29(7):884-900. https://doi.org/10.1108/ JMP-07-2012-0198 
Velada R, Caetano A, Michel JW, Lyons BD, Kavanagh MJ (2007) The effects of training design, individual characteristics and work environment on transfer of training. Int J Train Dev 11(4):282294. https://doi.org/10.1111/j.1468-2419.2007.00286.x

Williams V, Ciarrochi J, Deane FP (2010) On being mindful, emotionally aware, and more resilient: longitudinal pilot study of police recruits. Aust Psychol 45(December):274-282. https://doi.org/ 10.1080/00050060903573197

Xiao J (1996) The relationship between organizational factors and the transfer of training in the electronics industry in Shenzhen. China Human Resource Development Quarterly 7(1):55-73. https://doi. org/10.1002/hrdq.3920070107
Yamkovenko B, Holton E (2010) Toward a theoretical model of dispositional influences on transfer of learning: a test of a structural model. Hum Resour Dev Q 21(4):381-410. https://doi.org/10. 1002/hrdq. 20054

Zubairy NFAA, Mozie NM, Ghazali N (2015) Work environment and training transfer: the moderating effects of motivation. Proceedings of 2014 2nd International Conference on Technology, Informatics, Management, Engineering and Environment. TIME-E 2014 194-199. https://doi.org/10.1109/TIME-E.2014.7011617

Publisher's Note Springer Nature remains neutral with regard to jurisdictional claims in published maps and institutional affiliations. 